\title{
A PERMANÊNCIA DE LEANDRO GOMES DE BARROS: ATUALIDADE E RECEPÇÃO DO FOLHETO O DINHEIRO
}

\author{
Luzia Rita Nunes de Lira* \\ José Hélder Pinheiro Alves**
}

\begin{abstract}
Resumo: Nos últimos anos, com o advento dos estudos culturais, que passaram a valorizar a literatura produzida por grupos marginais e classes populares, a literatura de cordel passou a ter uma visibilidade maior e começou a ser levada com mais frequência para o espaço escolar. Como qualquer gênero literário, a literatura de folhetos também pode ser um instrumento na formação de leitores. Neste artigo, refletimos sobre um experimento realizado no ensino médio com a literatura de cordel. Analisamos e relatamos o momento de recepção do folheto $O$ dinheiro, de Leandro Gomes de Barros. Um dos objetivos do trabalho é refletir sobre a atualidade e a recepção de cordéis satíricos com leitores em formação. Para o estudo analítico do cordel nos embasamos em Bakhtin (2008), Northrop Frye (1957) que trazem importantes reflexões sobre sátira. Quanto ao trabalho com a literatura em sala de aula nos apoiamos nas contribuições de estudiosos como Lúcio e Pinheiro (2012); Cosson (2009) e Colomer (2007). Os resultados revelam a atualidade do folheto, uma vez que possibilitou uma atualização de temas como a corrupção, a desonestidade e a esperteza.
\end{abstract}

Palavras-chave: Leandro Gomes de Barros. O dinheiro. Sátira.

\begin{abstract}
In recent years, with the advent of cultural studies, which began to appreciate the literature produced by marginal groups, string literature began to have greater visibility and to be taken to the school environment. Like any literary genre, literature brochures can also be instrumental in the formation of readers. In this article, we reflect on an experiment conducted in high school with the string literature. We analyze and report the moment of reception of the brochure Money, written by Leandro Gomes de Barros. One of the goals of this paper is to reflect on the actuality and the reception of satirical string literature in the formation of readers. For the analytical study of the string literature we base our assumptions on Bakhtin (2008) and Northrop Frye (1957), who provide important reflections on satire. As for the work with the literature in the classroom, we rely on the contributions of scholars such as Lucius and Pinheiro (2012); Cosson (2009) and Colomer (2007). The results show the relevance of the leaflet, since it allowed an update of issues such as corruption, dishonesty and cunning.
\end{abstract}

Keywords: Leandro Gomes de Barros. Money. Satire.

\section{Considerações iniciais}

A obra do poeta Leandro Gomes de Barros a que temos acesso revela, dentre outros aspectos, um viés satírico dos mais agudos e, portanto, uma atualidade que pode ser verificada na leitura dos mais diversos folhetos. Narrativas como Viagem ao céu, O cavalo que defecava dinheiro, Juvenal e o dragão, Cancão de fogo, revelam a diversidade de temas e a percepção do poeta sobre a sociedade brasileira de seu tempo (final do século XIX e início do século $\mathrm{XX}$ ). Toda esta riqueza ficou e permanece fora das indicações de leitura em sala de aula. Se por um lado, atualmente, o cordel está chegando ao espaço escolar, por outro, boa parte do material que chega está contaminado por um viés fortemente pragmático, que transforma o folheto numa cartilha para se ensinar os mais diversos conteúdos - normas gramaticais,

\footnotetext{
* Mestrado em Linguagem e Ensino pela UFCG e Professora da educação básica do Estado de Pernambuco. Endereço eletrônico: luziajlh @ hotmail.com

** Pós-Doutor em Literatura Brasileira e Professor de Literatura Brasileira e Literatura Infantil da UFCG, onde orienta pesquisas no âmbito do ensino de Literatura na pós-graduação em Linguagem e Ensino. Endereço eletrônico: helderpin@uol.com.br
} 
ensinamento sobre prevenção de doenças, normas para economizar água, dentre tantos outros assuntos ${ }^{1}$.

Neste artigo, apresentamos uma apreciação do folheto $O$ dinheiro, de Leandro Gomes de Barros e o relato de uma vivência de sala de aula com o referido texto. Será observado como o viés satírico que caracteriza a obra do poeta é captado pelo jovem leitor, em sua maioria distante da tradição de leitura do folheto, mesmo habitando regiões onde a circulação deste gênero foi bastante intensa.

A concepção de sátira menipéia, desenvolvida por Bakhtin (1981) articula-se de modo bastante preciso com a obra de Leandro e será retomada nesta leitura. As questões levantadas pelo experimento de leitura apontam para a necessidade de se levar a um público cada vez maior uma literatura que, à margem do beletrismo do início do século XX, se construiu fora do centro, com um forte caráter de denúncia social. Optou-se por uma metodologia centrada no diálogo texto versus leitor, no compartilhamento (COLOMER, 2007) da leitura. O viés da oralidade, marca da literatura de cordel e bastante acionado na vivência, aponta para um procedimento que privilegia diferentes realizações orais na sala de aula. Esse procedimento resulta sempre numa experiência rica e estimulante para os leitores e respeita uma característica básica do folheto que, ao mesmo tempo que é escrito, conserva elementos marcantes de oralidade.

\section{A atualidade da sátira: breve análise de $O$ dinheiro}

O folheto $O$ dinheiro é composto por 34 sextilhas com esquema rímico que segue a tradição dos folhetos nordestinos ABCBDB, ou popularmente chamado de xaxaxa. Nele, encontramos a história de um inglês ${ }^{2}$ que suborna um vigário fazendo-o realizar um enterro cristão para o seu cachorro de estimação. O padre, ao saber que o cachorro havia deixado um testamento que o beneficiaria, passa por cima das leis da igreja e realiza o dito enterro.

$\mathrm{O}$ enredo divide-se em duas partes. A primeira, nas estrofes 1 a 16 e 32 a 35 , o autor apresenta diversas situações em que o dinheiro é destaque. Já na segunda, as estrofes 17 a 31, narra-se a história "verídica" do enterro cristão do cachorro. Veja-se a estrutura da primeira parte

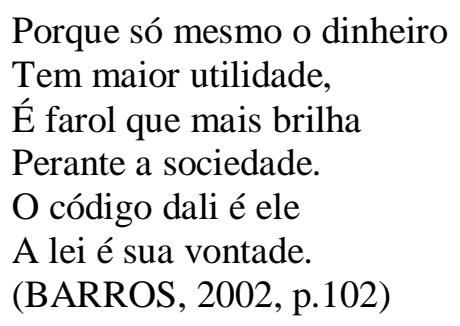

Nesses versos, é possível inferir que as instituições tidas como moralmente irrepreensíveis e poderosas são criticadas pelo poeta, que as desmascara, trazendo à luz os desmandos da igreja, do poder judiciário e político e até mesmo a família. A visão não tem nada de idealismo e o estilo é direto, como se pode observar:

\footnotetext{
${ }^{1}$ Uma discussão a respeito do uso pragmático da literatura de cordel pode ser encontrada em Alves (2011)

${ }^{2}$ Vale salientar que o inglês faz parte de uma série de folhetos, em que Leandro satirizava essa figura e que Diégues Jr. (1986) classificou como tema "Os estrangeiros no Brasil".
} 
$\mathrm{O}$ homem tendo dinheiro

Mata até o próprio pai,

A justiça fecha os olhos

A polícia lá não vai,

Passam-se cinco ou seis meses

Vai indo o processo cai
Ainda que vá a júri

Compra logo atenuante,

Dá um unto aos jurados

Se livra no mesmo instante,

Tem o juiz a favor,

Jurados e assim por diante

(BARROS, 2002, p.102)

Outro fator de destaque nesse poema é a presença da comparação do ser humano com o animal. Acreditamos que o autor buscava suscitar a reflexão em torno do tema discutido no folheto: o valor do homem na sociedade, que, tendo dinheiro vale muito, se não, até mesmo um animal vale mais.

Pois o homem sem dinheiro
É como um velho demente,
Um gato que não tem unha,
Cobra que não tem dente
Cachorro que não tem faro
Cavalo magro e doente.

(BARROS, 2002, p.103)

Northrop Frye (1973), ao refletir sobre a sátira, comenta que "chamar um homem de porco ou jaritataca ou uma mulher de cadela proporciona uma satisfação fortemente limitada, pois muitas das qualidades desagradáveis do animal são projeções humanas." (FRYE, 1957, p.221). É justamente nessa perspectiva de destacar as qualidades desagradáveis do homem, que não tem dinheiro, que o autor constrói tais comparações com os animais. Entendemos que, nesse folheto, a revelação da moral, implícita nos versos, demonstra duas características essenciais à sátira: "O humor e o ataque" (FRYE, 1973). Baseado na fantasia e nas comparações entre o homem e o animal, o autor ataca a ganância pelo dinheiro, presente em todas as instituições sociais, e que torna o homem, sem dinheiro, inferior perante a sociedade.

Também podemos destacar que o discurso do poeta tem uma forte ligação com o seu conhecimento de mundo, uma vez que essa aproximação do homem com a natureza é típica da relação existente entre o homem sertanejo e o seu universo.

A segunda parte do folheto tenta comprovar tudo que foi afirmado na primeira, contando a história "verídica" do inglês que consegue corromper a instituição considerada uma das mais poderosas da época em que o folheto foi publicado: a igreja católica, cuja missão era considerada sublime. Isso só foi possível porque, no testamento do animal, constava como herdeiro o vigário. $\mathrm{O}$ enredo, portanto, destaca-se pela denúncia e o faz, muitas vezes, através do riso, da ironia, tentando expor a verdade sem sofrer sanções por isso. As expressões satíricas, presentes na maior parte das produções do poeta, recorrem à possibilidade de um riso crítico, que pressupõe a superioridade de quem ri face ao alvo do riso ou suscitado pelos defeitos daquilo ou de quem se ri.

Ele antes de morrer Um testamento aprontou Só quatro contos de réis Para o vigário deixou Antes do inglês findar $\mathrm{O}$ vigário suspirou.
Coitado! Disse o vigário, De que morreu esse pobre? Que animal inteligente! Que sentimento tão nobre! Antes de partir do mundo 
A sátira é enfatizada pelo discurso do padre, que demonstra uma brusca mudança de comportamento (fala dócil), de atitude (o suspiro) e da atribuição de sentimento ao animal. Segundo Frye (1957),

Se um satirista apresenta, digamos um clérigo como tolo ou hipócrita, ele não está, qua satirista, atacando nem um homem nem uma igreja [...]. Ele esta atacando um mau homem protegido por sua igreja, e tal homem é um monstro gigantesco: monstruoso porque não é o que deveria ser gigantesco porque protegido por sua posição e pelo prestígio dos bons clérigos o hábito poderia fazer o monge, se não fosse pela sátira. (op. cit., p. 224)

Portanto, o ataque feito à instituição religiosa, nesse folheto, dá-se através do desmascaramento de um mau clérigo, protegido por sua igreja, o que não representa a composição geral dessa instituição, que, para o autor, continua sendo vista como sublime e, justamente por isso, necessita desse desmascaramento.

Encontramos, também, nesse folheto, uma grande aproximação com a sátira menipeia formulada por Bakhtin (1981), ao estudar as obras de Luciano de Samósata (escritor da antiguidade clássica). A teoria do filósofo russo contribui para que compreenda-se melhor as produções do cordelista paraibano, e mais especificamente, $o$ folheto $O$ dinheiro.

As sátiras de Luciano são, no conjunto, uma autêntica enciclopédia da sua atualidade: são impregnadas de polêmica aberta e velada com diversas escolas ideológicas, filosóficas, religiosas e científicas, com tendências e correntes da atualidade, são plenas de imagens e figuras atuais ou recém-desaparecidas, dos "senhores das ideias" em todos os campos da vida social e ideológica (citados nominalmente ou codificados), são plenas de alusões a grandes e pequenos acontecimentos da época, perscrutam as novas tendências da evolução do cotidiano, mostram os tipos sociais em surgimento em todas as camadas da sociedade. (BAKHTIN, 1981, p. 102).

Percebemos que, assim como as obras de Luciano "são impregnadas de polêmica aberta e velada com diversas escolas ideológicas, filosóficas, religiosas e científicas", também o folheto em análise se utiliza desses procedimentos para compor seu enredo, uma vez que coloca em discussão, em forma de diálogo com o interlocutor, as atitudes e reações do vigário e do bispo, sinalizadas pela presença do ponto de interrogação, que abre espaço para a reflexão da temática, veja-se:

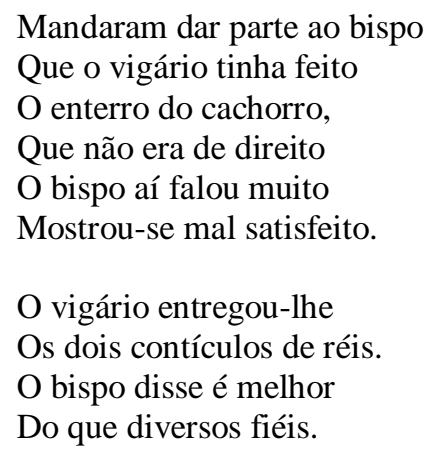

\author{
E disse: provera Deus \\ Que assim lá morresse uns dez \\ E se não fosse o dinheiro? \\ A questão ficava feia \\ Desenterrava o cachorro \\ $\mathrm{O}$ vigário ia pra cadeia \\ Mas como o cobre correu \\ Ficou qual letras na areia \\ (BARROS, 2002, p.103-104)
}


Novamente o discurso entra no poema como forma de satirizar. Dessa vez é o discurso do bispo que irá destacar o efeito satírico, demonstrado pela mudança de tom na fala e nas atitudes do bispo perante a situação ocorrida. Além disso, percebemos que essas estrofes encerram a segunda parte sem, contudo, encerrar o poema, pois há, nesse momento, um retorno à primeira parte do folheto, em que o autor vai apresentar, novamente, situações em que o dinheiro é determinante das ações humanas.

\author{
Judas era um homem santo \\ Pregava a religião \\ Era discípulo de Cristo, \\ Tinha toda direção \\ Porém por 30 dinheiros \\ Dispensou a salvação.
}

\author{
Havendo muito dinheiro \\ Casa-se irmã com irmão, \\ $\mathrm{O}$ bispo dispensa um quarto \\ Vai ao papa outro quinhão \\ $\mathrm{O}$ vigário dá-lhe o unto \\ E porque não casam, então? \\ (BARROS, 2002, p.104)
}

Como se pode observar, o poeta satiriza o Inglês, a igreja católica na figura de seus representantes hierárquicos, critica o poder judiciário, revela as fraquezas humanas perante o dinheiro, tudo isso em um tom mordaz, porém jocoso. A forma satírica com que o autor critica essas instituições confere atualidade à obra do poeta.

Feito este rápido incurso analítico do poema, passemos à vivência de leitura com o folheto em sala de aula. Nela pudemos perceber que a atualidade temática aproxima os leitores a obra literária suscitando o envolvimento dos alunos com o texto.

\section{Permanência e atualidade: recepção do folheto $O$ dinheiro}

A experiência aconteceu em Teixeira-PB, cidade que tem uma histórica ligação com a literatura popular ${ }^{3}$. A escola, estabelecimento da rede pública, em que realizamos o experimento, funciona nos turnos matutino, vespertino e noturno, atendendo a uma clientela escolar composta por 822 alunos; os turnos são distribuídos em ensino Fundamental e Médio. O corpo docente que leciona na escola, segundo fonte cedida pela secretária da mesma, é formado por 2 professores com nível médio e 29 com nível superior. Quanto aos discentes, são alunos de nível social médio e baixo.

Através dos dados coletados com a aplicação de um questionário, montamos um breve perfil dos participantes desta pesquisa, que sintetizamos da seguinte forma: Era uma turma de terceira série do Ensino Médio, composta por 12 alunos, 8 do sexo masculino e 4 do sexo feminino, com idades entre 16 e 19 anos, a maioria residente na zona urbana (apenas uma aluna morava na zona rural). Quanto aos hábitos de leitura, 5 alunos responderam que mantinham esse hábito, 6 responderam que não costumavam ler e 1 aluno não respondeu a essa pergunta. Quanto ao tipo de leitura que eles realizam, obtivemos os seguintes dados:

\footnotetext{
${ }^{3}$ Teixeira, localizada no sertão paraibano, é uma cidade tida por alguns estudiosos e poetas como berço da poesia popular do nordeste brasileiro, devido ao fato de ter, em suas origens, nomes de muitos dos mais renomados cantadores repentistas do Nordeste como, por exemplo, Inácio da Catingueira, Romano de Mãe d'água, Agostinho Nunes da Costa e seus filhos Ungolino Nunes da Costa e Nicandro Nunes da Costa, Francisco das Chagas Batista, Pedro Batista, e Zé Limeira, conhecido como poeta do absurdo, entre outros.
} 
Gráfico1-Questionário respondido pelos alunos colaboradores-10ª Questão - Com que frequência você lê:
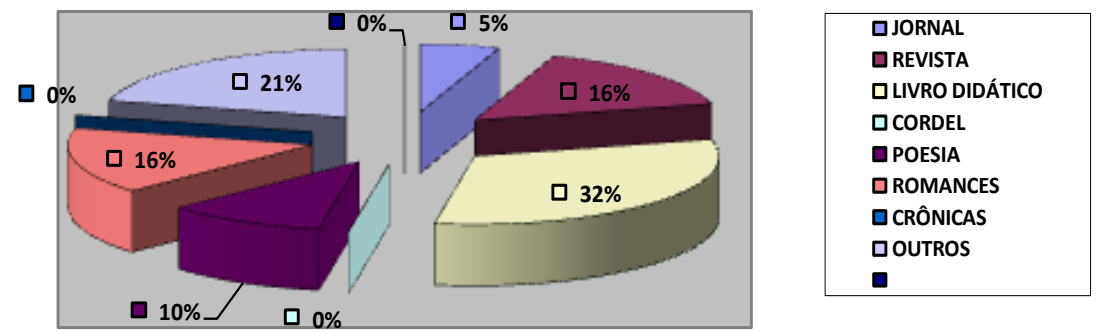

Fonte (LIRA, 2012)

Pudemos perceber que a maioria dos alunos afirma realizar, com frequência, a leitura do livro didático, o que, talvez seja influência das ações da professora que, em seu discurso, afirma utilizar-se muito desse suporte. Também percebemos que a leitura literária ocupa um espaço de desvantagem em comparação com a leitura de jornais e de revistas, porém, acreditamos ser positivo o fato de nossos colaboradores realizarem com frequência algum tipo de leitura.

Ao serem questionados se conheciam algum poeta popular, 5 alunos responderam que não e 6 responderam que sim. Porém, ao completarem a questão, citando o poeta popular que conheciam, indicaram nomes como Carlos Drummond de Andrade, Augusto dos Anjos, Fernando Pessoa, Pedro Bandeira e João Cabral de Melo Neto e Chorão (Vocalista e compositor do grupo musical CBJr.). Essas respostas demonstraram que a turma não consegue fazer distinção entre poetas, romancistas ou mesmo compositores musicais e também não identificam nenhum poeta realmente popular. Quanto aos escritores que eles conheciam, dentre uma lista que lhes foi apresentada no questionário, obtivemos os seguintes resultados:

Gráfico 2 - Questionário respondido pelos colaboradores - $14^{\mathrm{a}}$ Questão- Dentre os escritores abaixo identifique o(s) que você conhece.

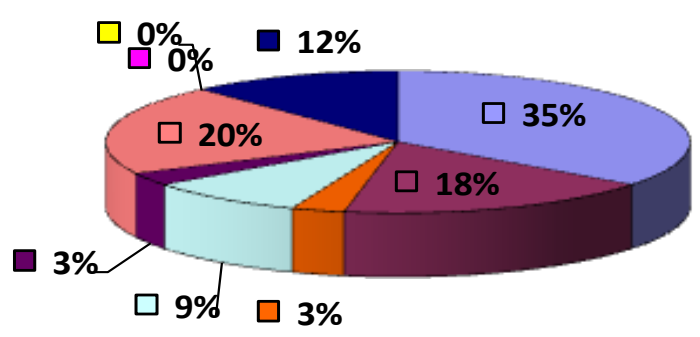

$\square$ Carlos Drummond de Andrade
$\square$ Cecília Meireles
$\square$ Leandro Gomes de Barros
$\square$ Pedro Bandeira
$\square$ Patativa do Assaré
$\square$ Olavo Bilac
$\square$ Arlindo Lopes
$\square$ Jandhui Dantas
$\square$ José Limeira

Fonte (LIRA, 2012)

Percebemos que é grande ainda o conhecimento acerca dos escritores já renomados e cuja relevância está cristalizada na sociedade, enquanto o conhecimento dos escritores populares se apresenta de modo tímido, mesmo aqueles escritores nascidos em sua cidade, como é o caso do poeta Zé Limeira, que apenas quatro alunos afirmaram conhece-lo isso representa menos de $40 \%$ da turma. Quando interrogados se já haviam lido textos dos escritores que afirmaram conhecer, tivemos respostas que variavam entre os que confirmavam e citavam títulos de obras e os que afirmavam terem lido, mas que não lembravam títulos das obras. Apenas 3 alunos não haviam lido 
nenhuma obra dos escritores, e 2 alunos não responderam à questão. Quanto à leitura de cordel, 09 alunos responderam que já haviam lido algum folheto na vida, e 3 responderam que nunca haviam lido nenhum folheto.

Concluímos a análise destes dados coletados através do questionário observando que o contato que esses alunos tiveram durante a educação básica (visto que se encontravam na última etapa) com a literatura foi bastante superficial e que a aproximação com a leitura literária é vaga.

Para realizarmos a leitura do folheto $O$ dinheiro, partimos do pressuposto de que trata Colomer (2007), quando afirma que "compartilhar a leitura significa socializála, ou seja, estabelecer um caminho a partir da recepção individual até a recepção no sentido de uma comunidade cultural que a interpreta e avalia." (COLOMER, 2007, p.147).

Preparamos o ambiente (a sala de vídeo cedida pela direção da escola), dispondo as carteiras em círculos para facilitar a interação durante a leitura e o debate e pregamos notas de dinheiro de brinquedo para chamar atenção e criar expectativas quanto à leitura.

Iniciamos a aula comentando que havia nas carteiras, algo de que todos gostavam e, de imediato, alguns começaram a rir e confirmar com gestos afirmativos. Então, perguntamos o que fariam se tivessem ou ganhassem muito dinheiro; nesse momento, houve uma boa participação, conforme revelam as respostas a seguir:

Aluno 1: Investiria para não gastar tudo de uma vez;

Aluno 2: Criaria uma marca de skate com o meu nome;

Aluno 3: Abriria uma escola de música aqui em Teixeira;

Aluno 4: (criticando a escolha do colega): Tu pensa pequeno, querer abrir uma escola de música aqui.

Houve risos de alguns e o clima parecia bem descontraído; então, indagamos sobre o que eles achavam do poder que o dinheiro exercia na sociedade e constatamos, novamente, uma boa participação, veja-se:

Aluno 5: É hoje em dia quem manda é o dinheiro;

Aluno 6: O prefeito de XXXX só ganhou as eleições porque comprou os votos;

Aluno 7: Se um rico comete um assassinato está livre;

Aluno 2: Eu soube de uma mulher que roubou uma margarina e passou mais de um mês presa;

Aluno 1: É! se alguém chega a um hospital e tem dinheiro recebe um tratamento diferente daquele que não tem.

A turma, como um todo, mostrou-se bastante interessada no tema que era posto em discussão, mesmo os que não participavam fazendo comentários se mostravam através de gestos e olhares afirmativos ou mesmo através do riso. Ainda não havíamos realizado a leitura, contudo percebíamos grande envolvimento dos alunos e, assim, acreditamos ter cumprido com êxito o que Rildo Cossom (2009, p.77) chama de "motivação", quando afirma que "A motivação consiste em uma atividade de preparação, de introdução dos alunos no universo a ser lido".

Distribuímos entre eles o folheto para que pudessem perceber os aspectos físicos da obra. A seguir, pedimos que observassem a capa, a xilogravura e comentamos que aqueles eram aspectos peculiares da Literatura de Cordel. 
Sugerimos, então, que observassem e comentassem o que eles percebiam através da xilogravura, se, a partir dali, já dava pra se ter uma ideia do que tratava o enredo da obra.

Aluno 3: Parece com a história do Auto da Compadecida;

Aluno 1: É mesmo, o testamento do cachorro;

Aluno 5: Alguém já assistiu?

Aluno 8: Onde você viu isso?

Aluno 1: Na capa, o subtítulo. Todo mundo já assistiu, né!

Aluno 8: É mesmo.

Iniciamos a leitura seguindo a sugestão de Marinho e Pinheiro (2012, p. 84) de que "a leitura oral dos folhetos é indispensável. Portanto a primeira atividade deve ser a leitura em voz alta". Realizamos, então, a leitura. Notamos que muitos alunos riram enquanto líamos a estrofe 14:

A moça tendo dinheiro

Sendo feia como a morte

Caracteriza-se, enfeita-se.

Sempre melhora de sorte

Mais de mil aventureiros

A desejam por consorte

(BARROS, 2002, p.103)

29:

Outra estrofe que também gerou risos durante a leitura por nós realizada foi a

$\mathrm{O}$ vigário entregou-lhe

Os dois contículos de réis

O bispo disse é melhor

De que diversos fiéis

E disse prouvera Deus

Que assim lá morresse um dez

(BARROS, 2002, p.104)

Encerramos esse momento e propusemos então que fizessem nova leitura, dessa vez, individual, tentando destacar as estrofes que mais lhe chamassem a atenção. Conforme Marinho e Pinheiro (2012, p.84), "repetidas leituras em voz alta é que vão tornando o folheto uma experiência para o leitor". Logo obtivemos a participação dos alunos, que fizeram a leitura de algumas estrofes. O Aluno 1 leu a estrofe 32:

O dinheiro só não pode

Privar do dono morrer,

Parar o vento no ar

E proibir de chover

O resto se torna fácil

Para o dinheiro fazer

(BARROS, 2002, p. 104)

E afirmou: "nem tudo o dinheiro pode, né? $\mathrm{O}$ aluno 9 leu para a turma a estrofe que mais lhe chamou atenção: 
O homem tendo dinheiro

Mata até o próprio pai,

A justiça fecha os olhos

A polícia lá não vai,

Passam-se cinco ou seis meses

Vai indo o processo cai.

(BARROS, 2002, p.102)

E, a seguir, comentou: "a pessoa não se importa nem com a família, tendo dinheiro". Então, relembramos que alguns dos comentários surgidos no início da aula se efetivavam na leitura do texto. Indagamos se havia alguma estrofe que eles achavam mais engraçada; queríamos observar se eles percebiam o aspecto satírico da obra. Então o aluno 5 leu a estrofe 14, justamente a que havia provocado o riso discreto enquanto realizávamos a leitura. Ao percebermos que certo silêncio tomava conta da sala, continuamos a sugerir que alguém destacasse alguma outra estrofe que tenha achado engraçada. Então o aluno 7 fez a leitura da estrofe 13:

O bacharel por dinheiro

Só macaco por banana

Ou gato por gabiru

Ou um guaxinim por cana

Só sagüi pela resina

Ou bode por jutirana.

(BARROS, 2002, p. 107)

"É bem engraçada a comparação!"

O debate seguiu-se ainda por alguns minutos em que obtivemos comentários que diziam o seguinte: “é engraçado, mas é desse jeito que acontece!”; "É tudo verdade!". Esses comentários remetem a uma das peculiaridades da sátira menipeia apontadas por Bakhtin (1981), quando menciona que ela gera uma espécie de reflexão sobre os problemas do mundo através de uma ousada imaginação, de fato, podemos perceber que a leitura do texto impulsionou a reflexão acerca dos problemas humanos, fazendo com que os leitores se posicionassem a favor do que estava escrito. Outra observação interessante é que os nossos colaboradores realizaram a identificação direta do texto com os problemas sociais da atualidade, mesmo sendo um texto escrito em época distinta da atual, e essa atualidade temática é uma característica de muitos dos folhetos de Leandro Gomes de Barros.

O decorrer da experiência com outros folhetos comprovou que o cordel pode ter uma recepção significativa se for trabalhado de modo a permitir o diálogo do texto com o leitor e a aproximação da narrativa com a vida de cada leitor. ${ }^{4}$ Neste sentido, pode-se falar de atualidade da obra, uma vez que foram ressignificadas num contexto de quase cem anos depois.

\footnotetext{
${ }^{4}$ Foram realizadas leituras de mais dois folhetos de Leandro Gomes de Barros, atentando para a construção do aspecto satírico. Foram eles: $O$ cavalo que defecava dinheiro e As proezas de um namorado mofino. O trabalho completo resultou em uma Dissertação de Mestrado do Programa de Pós Graduação em Linguagem e Ensino da UFCG, intitulada: SATIRA EM LEANDRO GOMES DE BARROS: uma experiência de leitura com alunos do $3^{\circ}$ ano do Ensino Médio.
} 


\section{Considerações finais}

Visto que consideramos a Literatura de Cordel uma manifestação de grande valor cultural e que acreditamos que ela deva ser experimentada pelos leitores, adotamos, para a realização desta pesquisa, metodologias que oportunizassem o encontro dos leitores com a experiência cultural ali representada.

Primeiramente, devemos explicitar que, após refletirmos sobre nossa experiência de leitura, podemos afirmar que, de fato, ao optarmos por desenvolver a experiência, tendo como objeto poemas satíricos, eliminamos uma barreira inicial, que era o contato dos alunos com a Literatura de Cordel de forma agradável, comprovada pelo envolvimento deles com as leituras e pelos diversos momentos de descontração e riso.

Quanto ao nosso questionamento em relação ao modo como se daria a recepção dos textos satíricos, podemos afirmar que a recepção se deu a partir da aproximação dos textos com a realidade dos alunos, proporcionada pela atualidade do folheto lido em sala de aula. Podemos de certa forma, dizer que nossas hipóteses iniciais foram confirmadas, visto que, durante os debates suscitados, os alunos, mesmo sem mencionarem termos teóricos, atentaram para o fato de que, de forma jocosa, a sátira fazia a diferença naqueles folhetos, pois instigava a reflexão acerca de determinadas situações e da condição humana, Confirmando, também, a idéia de permanência efetiva da obra de Leandro Gomes de Barros.

Há que se destacar, ainda, o ganho metodológico da experiência. Podemos afirmar que quando buscamos um modelo de ensino que privilegia o diálogo texto versus leitor temos mais possibilidade de proporcionar aos leitores em formação um autonomia de leitura e não a mera reprodução de saberes constituídos sobre a literatura. Por fim, o experimento revela também o quando se perde por não trazer para sala de aula a literatura de cordel, sobretudo a obra de poetas de valor já confirmado. Ratificamos: o cordel enquanto literatura, narrativa e não como instrumento de didatização de conteúdos. Esta perspectiva até pode ser trabalhada por profissionais de história, geografia e outras áreas, mas por certo, pouco contribui para a formação de leitores de literatura.

\section{Referências}

ABREU, M. História de cordéis e folhetos. Campinas: Mercado de Letras, 1999.

AGUIAR, V. T. e BORDINI, M. da G. A formação do leitor: alternativas metodológicas. Porto Alegre: Mercado Aberto, 1988, 176p.

ALVES, J. H. P.; MARINHO, A. C. L. O cordel no cotidiano escolar. São Paulo: Cortez, 2012. (Coleção Trabalhando com... na escola).

Literatura de cordel na escola: vivência artística ou utilitarismo. In: LIMA, M. A. F.; ALVES FILHO, F.; COSTA, C. S. S. M. (Org.). Colóquios linguísticos e literários: enfoques epistemológicos, metodológicos e descritivos. Teresina: EDUFPI, 2011, v. 1, p. 175-192. 
et al. (Orgs.) Literatura popular e ensino: leituras, atitudes e procedimentos. In: Literatura e formação de leitores. Campina Grande: Bagagem, 2008.

. (Org). Pesquisa em Literatura. Campina Grande: Bagagem. 2. ed, 2011.

. Tesouros da poesia popular para crianças e jovens. Boitatá - Revista do GT de Literatura Oral e Popular da ANPOLL. Disponível em: http://www2.uel.br/revistas/boitata/?content=volume_5_2008. htm. Acesso em $15 / 03 / 2008$.

AYALA, M. I. N. Aprendendo a aprender a cultura popular. In: PINHEIRO, H. (Org). Pesquisa em Literatura. Campina Grande: Bagagem, 2003.

BAKHTIN, M. Problemas da Poética de Dostoiévski. Trad. de Paulo Bezerra. Rio de Janeiro: Forense Universitária, 1981.

BARROS, L. G. de. O dinheiro (o testamento do cachorro). In: MEDEIROS, I. No reino da poesia sertaneja: antologia Leandro Gomes de Barros. João Pessoa: Ideia, 2002.

BATISTA, S. N. Antologia da Literatura de Cordel. Natal: Fundação José Augusto, 1977.

BOSI, A. A interpretação da obra literária. In: Céu e Inferno, São Paulo: Ática, 1988. Disponível em : 〈http://www.cesargiusti.bluehosting.com.br/Apoio/bosi.htm>. Acesso em $15 / 11 / 2012$.

COLOMER, T. Andar entre livros. Trad. Laura Sandroni. São Paulo: Global, 2007.

COSSON, R. Letramento Literário: teoria e prática. 1. ed. São Paulo: Contexto, 2009.135p.

CURRAN, M. J. A Literatura de Cordel. Recife. Universidade Federal de Pernambuco, 1973.

DIÉGUES JR. M et al. Literatura popular em verso: estudos. Belo Horizonte: Itatiaia, São Paulo/Rio de Janeiro: Edusp/Fundação Casa de Rui Barbosa, 1986.

FARIAS, A. S. Encontro com Lalino e Cancão: estranhamentos e parecenças na vivência do texto literário em sala de aula. Campina Grande, 2010.162 f.: il. col. (Dissertação Mestrado em Linguagem e Ensino Universidade Federal de Campina Grande, Centro de Humanidades).

FRYE, N. Anatomia da Crítica, São Paulo, Cultrix, 1973, 362 p.

GOLDSTEIN, N. Versos, sons, ritmos. São Paulo, Ática, 1987. 
JAUSS, H. R. O prazer estético e as Experiências Fundamentais da Poiesis, Aesthesis e Katharsis. In: LIMA, L. (Org.). A literatura e o leitor: textos de estética da recepção. Rio de Janeiro: Paz e Terra, 1979.

A história da literatura como provocação à teoria literária. Trad. de Sérgio Tellaroli. São Paulo: Ática, 1994.

SILVA, M. V. Motivações para leitura literária no Ensino Médio. In: PINHEIRO, H.; ARISTIDES, J. (Org). Literatura e formação de leitores. Campina Grande: Bagagem, 2008.

TAVARES, M. Quem não leu ficou de fora? Proposta e Concepções de Leitura na coleção Literatura em Minha Casa. In: Leia Escola: Revista da Pós-Graduação em Linguagem e Ensino da UFCG. v. 8, n. 1, 2008/Campina Grande: 2008.

ZILBERMAN, R. Estética da recepção e história da literatura. São Paulo: Ática, 2004.

Recebido em: junho de 2013.

Aprovado em: outubro de 2013. 